\title{
UK Renal Registry 20th Annual Report: Chapter 6 Adequacy of Haemodialysis in UK Adult Patients in 2016: National and Centre-specific Analyses
}

\author{
Rhodri Pyart ${ }^{a}$, Winnie Magadi ${ }^{a}$, Retha Steenkamp ${ }^{a}$, Andrew Davenport $^{b}$ \\ ${ }^{\mathrm{a} U K}$ Renal Registry, Bristol, UK; ${ }^{\mathrm{b}}$ Royal Free Hospital, London, UK
}

\section{Keywords}

Adequacy · Haemodialysis · Urea reduction ratio

\section{Summary}

- Data regarding the urea reduction ratio (URR) were available for analysis from 63 renal centres and 74\% of the prevalent haemodialysis (HD) population in the UK.

- Fifty-one centres provided URR data on more than 90\% of prevalent HD patients.

- The proportion of patients in the UK who met the
Renal Association (RA) clinical practice guideline for URR (>65\%) has been stable between $88-89 \%$ since 2011.

- The median URR has been stable over the same period (75\%).

- There was persistent variation observed between centres, 15 centres attaining the RA clinical practice guideline in $>90 \%$ of patients and 42 centres attaining the guideline in $70-90 \%$ of patients.

- Over $95 \%$ of the prevalent HD population received dialysis three times a week but $26 \%$ did less than four hours per session.

- Median URR was similar between patients irrespective of dialysis session duration.
This article is licensed under the Creative Commons AttributionNonCommercial-NoDerivatives 4.0 International License (CC BYNC-ND) (http://www.karger.com/Services/OpenAccessLicense). Usage and distribution for commercial purposes as well as any
Rhodri Pyart

UK Renal Registry, Southmead Hospital, Southmead Road,

Bristol, BS10 5NB, UK

Email: renalregistry@renalregistry.nhs.uk 


\section{Introduction}

Measures of dialyser urea clearance have been the basis for assessing dialysis adequacy since the National Co-operative Dialysis Study (NCDS) [1]. Observational studies have shown that the minimum amount of dialysis a patient receives affects mortality although higher urea clearance targets in randomised clinical trials have not been shown to improve survival [2-4]. Of the two commonly used measures of dialyser urea clearance, the UK Renal Registry (UKRR) has historically reported the urea reduction ratio (URR), the percentage fall in serum urea following a mid-week dialysis session. Whilst the alternative $\mathrm{Kt} / \mathrm{V}$ is a better method for measuring dialysis dose because it takes account of the size of a patient and urea removal by ultrafiltration, it requires data items not routinely collected by all UK renal centres [5-6]. URR is the most commonly used measure of urea clearance in dialysis centres in Europe in daily practice [7] and predicts minimum dialysis dose in the majority of patients consistently with Kt/V [8]. Both measures can be influenced by failure to adhere to standardised sampling techniques and by urea rebound at the end of dialysis $[9,10]$.

The direct toxicity of urea and the extent to which dialyser urea clearance reflects the removal of other azotaemic toxins which may have greater impact on patient outcomes remains under debate. Increasing use of alternative dialysis regimens to the paradigm of thrice weekly short dialysis sessions upon which urea clearance models were developed may further challenge their validity as measures of dialysis adequacy in the future [11]. Despite such uncertainties, measures of urea clearance currently remain the basis for assessing dialysis adequacy in international guidelines which remain remarkably uniform in the minimum recommended amounts of dialyser urea clearance [12-14].

The UK Renal Registry (UKRR) collects data on patients with established renal failure (ERF) receiving haemodialysis (HD) from renal centres in England, Wales and Northern Ireland as well as from Scotland via the Scottish Renal Registry. This enables UK renal centres to compare performance to each other, to the national average and to the attainment of the minimum dose of HD, as defined by URR, in the Renal Association (RA) guidelines on dialysis adequacy.

Table 6.1 lists the current Renal Association audit measures relevant to haemodialysis patients and whether the audit measure is currently reported in the UKRR annual report [12]. Updated RA haemodialysis guidelines are due to be published in 2018.

The RA clinical practice guidelines for HD dose apply specifically to patients undergoing thrice weekly HD. In these patients, it is recommended that blood for biochemical measurement (including pre-dialysis urea for URR) should be taken before the mid-week dialysis session [12].

Table 6.1. Summary of recommended Renal Association audit measures relevant to haemodialysis adequacy

\begin{tabular}{lc}
\hline Haemodialysis adequacy RA audit measure & $\begin{array}{c}\text { Included in UKRR } \\
\text { annual report? }\end{array}$ \\
\hline
\end{tabular}

The proportion of patients in the main renal centre and its satellite units Partly who are on twice weekly haemodialysis

Varying levels of reporting between centres

Cumulative frequency curves of urea reduction ratio measured using a standard method of post-dialysis sampling

The proportion of patient non-attendances for haemodialysis sessions and the proportion of dialysis sessions shortened at the patient's request

The proportion of thrice weekly haemodialysis sessions which have prescribed treatment times less than four hours

The proportion of hospital (main and satellite unit) and home haemodialysis patients who are prescribed more frequent than thrice weekly haemodialysis
Yes, but data not presented in the cumulative frequency format

No Data not available

Yes

Partly Not for home haemodialysis patients 


\section{Methods}

Seventy renal centres in the UK submitted data electronically to the UKRR on a quarterly basis. Cambridge renal centre (Addenbrooke's) was unable to submit 2015 and 2016 data at patient level prior to the UKRR closing date for data submission but provided summary numbers of patients starting RRT by treatment modality. This centre is therefore excluded from most analyses in this chapter. The majority of UK centres have satellite units but for the purposes of this study the data from the renal centres and their associated satellite units were amalgamated. Data from two groups of patients were analysed. Firstly, analysis was undertaken using data from the prevalent adult HD patient population as of 30 September 2016. The UKRR electronically receive quarterly data extracts with the latest available result for each quarter, from renal centres in England, Wales and Northern Ireland (E,W\&NI). Data from Scotland were provided by the Scottish Renal Registry (SRR). For this analysis, data for URR were taken from the 3 rd quarter of 2016 unless that data point was missing in which case data from the 2 nd quarter were taken. The prevalent population only included patients receiving $\mathrm{HD}$ who were alive on September 30 2016. Data from those patients who had died before that date have not been included in the analysis. The second analysis involved adult incident patients who had commenced treatment with HD during 2015. For these patients, analysis was undertaken using the last recorded URR in the quarter in which the patient had started dialysis. The incident HD patient cohort was followed up for one year and the last recorded URR in the quarter after one-year follow-up was used for this analysis.

From 2015, quarterly HD sessional data as specified in version 4.2 of the UKRR renal dataset were increasingly being returned by many renal centres. It is hoped that in future, the number of dialysis sessions per week and time per dialysis session data can be augmented using these data items. Two centres, London Guys and Stevenage only returned these data items within the HD sessional data; hence data for these items were fully retrieved from the HD sessional data. However, the quality of the sessional data varied across centres and therefore was not used to augment quarterly data for the remaining centres at this time.

Data from patients known to be receiving more than or less than thrice weekly HD were omitted from the analysis for both the incident and prevalent population. Patients who had missing data for the number of dialysis sessions per week were assumed to be dialysing thrice weekly. However, because not all centres report frequency of $\mathrm{HD}$, it is possible that data from a small number of patients receiving $\mathrm{HD}$ at a different frequency were included in the analyses. Home HD patients were excluded from the analysis.

Analyses of the data from both groups of patients included the calculation of the median URR and of the proportion of patients who had achieved the RA guideline (as outlined below) in each of the renal centres, the UK countries as well as for the UK as a whole. The median URR and proportion of patients who achieved the RA guideline were also calculated separately for males and females. The number of dialysis sessions per week and the time per dialysis session is shown by renal centre.

All patients with data were included in the statistical analyses at a national level, although centres with fewer than ten patients, or providing less than $50 \%$ data completeness were excluded from the comparison between centres. The number preceding the centre name in each figure indicates the percentage of missing data for that centre.

The UK RA clinical practice guidelines [12] in operation at the time these data were collected, were as follows:

HD should take place at least three times per week in nearly all patients. Reduction of dialysis frequency to twice per week because of insufficient dialysis facilities is unacceptable.

Every patient receiving thrice weekly $H D$ should have consistently:

- either URR $>65 \%$

- or equilibrated $\mathrm{Kt} / \mathrm{V}(\mathrm{eKt} / \mathrm{V}$ ) of $>1.2$ (or single pool $\mathrm{Kt} / \mathrm{V}$ of >1.3) calculated from pre- and post-dialysis urea values, duration of dialysis and weight loss during dialysis.

To achieve a URR above $65 \%$ or $\mathrm{eKt} / \mathrm{V}$ above 1.2 consistently in the vast majority of the HD population clinicians should aim for a minimum target URR of $70 \%$ or minimum eKt/V of 1.4 in individual patients.

The duration of thrice weekly HD in adult patients with minimal residual renal function should not be reduced below 4 hours without careful consideration.

Patients receiving HD twice weekly for reasons of geography should receive a higher sessional dose of $H D$. If this cannot be achieved, then it should be recognised that there is a compromise between the practicalities of HD and the patient's long-term health.

Measurement of the 'dose' or 'adequacy' of HD should be performed monthly in all hospital HD patients and may be performed less frequently in home HD patients. All dialysis units should collect and report this data to their regional network and the UKRR.

Post-dialysis blood samples should be collected either by the slow-flow method, the simplified stop-flow method, or the stop dialysate flow method. The method used should remain consistent within renal units and should be reported to the Registry.

The RA clinical practice guidelines for HD dose apply specifically to patients undergoing thrice weekly HD. In these patients, it is recommended that blood for biochemical measurement (including pre-dialysis urea for URR) should be taken before the mid-week dialysis session [12].

The data were analysed using SAS 9.3.

\section{Results}

\section{Data completeness}

Sixty three of the $71 \mathrm{UK}$ renal centres submitted HD dose (URR) data to the UKRR (table 6.2). Data were available for $73.7 \%(N=15,501)$ of the total prevalent population $(N=21,041)$ treated with $\mathrm{HD}$ who met the inclusion criteria for these analyses.

Fifty-one centres reported URR data on more than $90 \%$ of their patients. Six centres reported URR data on less than $50 \%$ of prevalent patients (Carshalton, 
Table 6.2. Percentage completeness of URR data returns for prevalent patients on HD by centre, on 30/9/2016

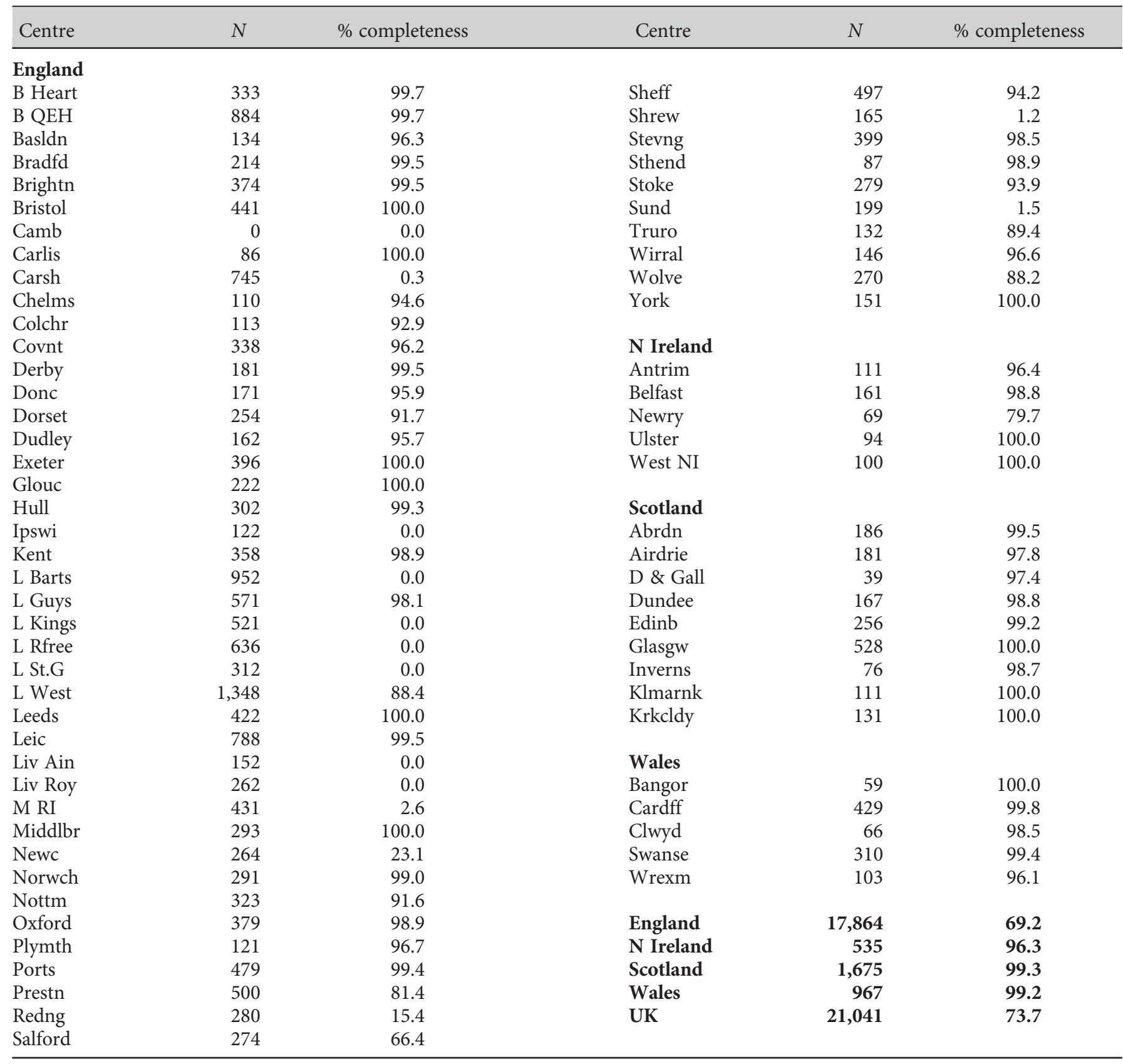

Manchester RI, Newcastle, Reading, Shrewsbury, Sunderland). URR data were not received from eight centres (Cambridge, Ipswich, London St Bartholomew's, London Kings, London Royal Free, London St Georges, Liverpool Aintree, Liverpool Royal Infirmary).

There was little change in the overall completeness of URR data submitted to the UKRR from most centres in 2016 compared with 2015, with an average change of
$1.2 \%$ (range: $-5.4 \%$ to $88.4 \%$ ). Any centre change may have occurred due to changes in computerised data bases and data extraction, or by centres moving to online $\mathrm{Kt} / \mathrm{V}$, or total $\mathrm{Kt} /$ Vurea including residual renal urea clearance rather than URR as the preferred measure of haemodialysis dose.

Eleven centres did not provide data on frequency of dialysis sessions, and 49 centres provided data on 
$>90 \%$ of patients (table 6.3). Eleven centres did not provide data on dialysis session times, and 45 centres provided data on $>90 \%$ of patients (table 6.4). In those centres not returning data, there appeared to be a common IT provider and locally collected data was not received by the UKRR. Ways of overcoming this problem in the future are being sought.

Of the total incident patient population $(N=4,879)$ who started HD during 2015 and meeting the inclusion criteria for URR analyses, $47.0 \%(N=2,298)$ had URR data available during the first quarter of treatment (data not shown). This was an increase from $43 \%$ in the 2014 incident population. Eight centres did not provide data for the first quarter of treatment, and 41 centres provided data on $>90 \%$ of incident patients during the first year.

\section{Achieved URR}

The median URR for prevalent HD patients was $75 \%$ but ranged between centres from 69-82\% (figure 6.1a).
There was evidence that the median URR for female HD patients at 78\% (centre range 73-85\%) (figure 6.1b) was greater than that of male HD patients, with a median URR at 74\% (centre range 68-80\%) (figure 6.1c).

There was evidence that the median sessional URR was lower for patients aged $<70$ years (median $75 \%$ ) compared to older patients $\geqslant 70$ years (median $76 \%$ ). Similarly, the median sessional URR was lower for both genders in the younger age group ( $<70$ years) compared to the older age group ( $\geqslant 70$ years of age): median URR of $77 \%$ for females $<70$ years of age compared to a median URR of $78 \%$ for female patients aged $\geqslant 70$ years. Similarly, for male patients aged $<70$ years of age the median URR of $73 \%$ was lower than for male patients aged $\geqslant 70$ years (median URR $74 \%$ ).

The current UK RA clinical guideline target is to achieve a minimum sessional URR of $65 \%$, and this was achieved in $87.5 \%$ of HD prevalent patients (centre range $70.8-95.7 \%$ ) (figure 6.2). A higher number of female patients achieved this minimum target $(92.1 \%$,

Table 6.3. Number of dialysis sessions for prevalent patients on HD by centre, on 30/9/2016

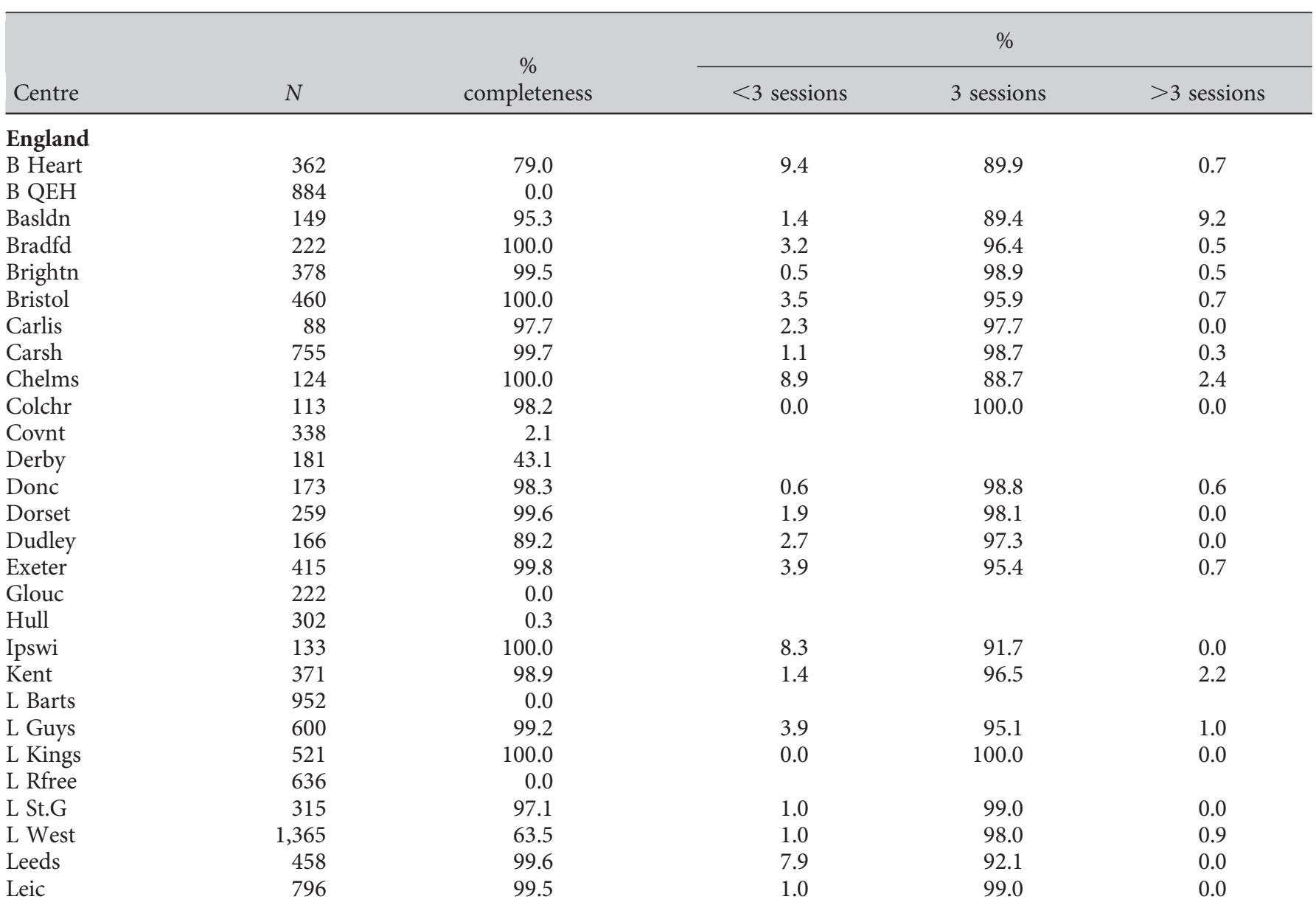


Table 6.3. Continued

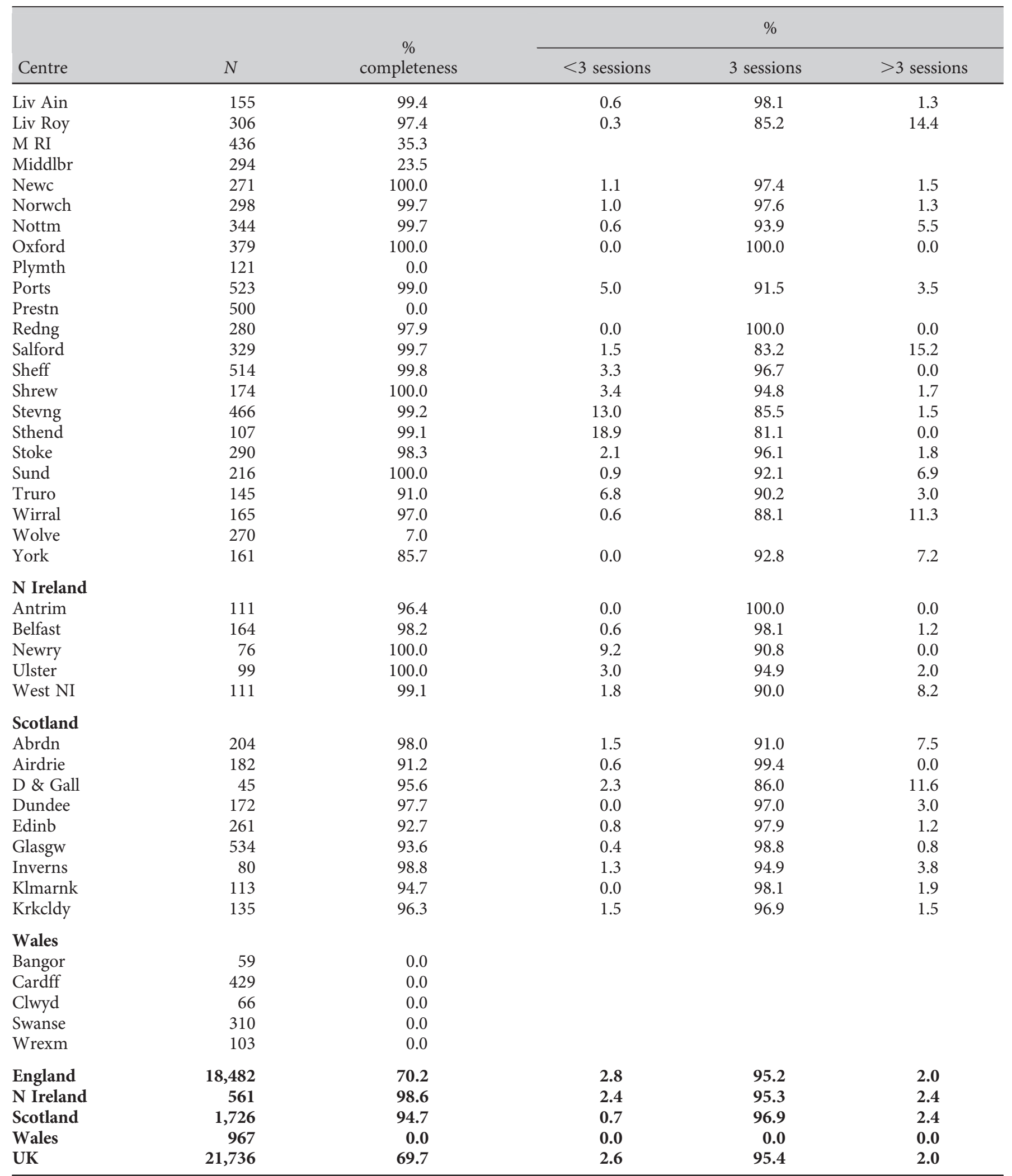

Blank cells denote no data returned by the centre or $<10$ patients in the renal centre or data completeness was $<50 \%$ 
Table 6.4. Time per dialysis session for prevalent patients on HD by centre, on 30/9/2016

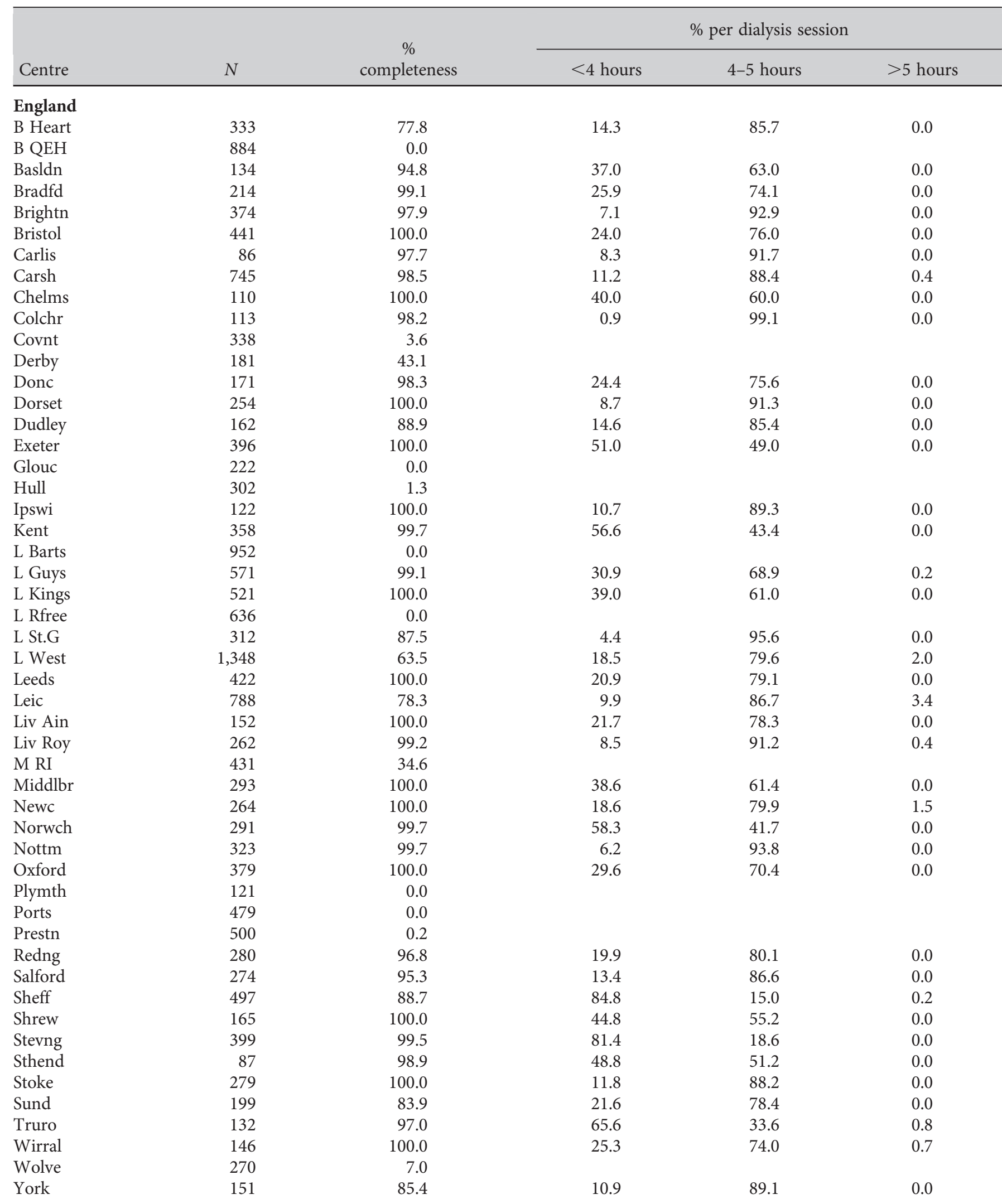


Table 6.4. Continued

\begin{tabular}{|c|c|c|c|c|c|}
\hline \multirow[b]{2}{*}{ Centre } & \multirow[b]{2}{*}{$N$} & \multirow{2}{*}{$\begin{array}{c}\% \\
\text { completeness }\end{array}$} & \multicolumn{3}{|c|}{$\%$ per dialysis session } \\
\hline & & & $<4$ hours & $4-5$ hours & $>5$ hours \\
\hline \multicolumn{6}{|l|}{ N Ireland } \\
\hline Antrim & 111 & 97.3 & 14.8 & 85.2 & 0.0 \\
\hline Belfast & 161 & 100.0 & 16.8 & 83.2 & 0.0 \\
\hline Newry & 69 & 100.0 & 52.2 & 47.8 & 0.0 \\
\hline Ulster & 94 & 100.0 & 12.8 & 87.2 & 0.0 \\
\hline West NI & 100 & 99.0 & 58.6 & 41.4 & 0.0 \\
\hline \multicolumn{6}{|l|}{ Scotland } \\
\hline Abrdn & 186 & 98.4 & 5.5 & 92.3 & 2.2 \\
\hline Airdrie & 181 & 98.9 & 13.4 & 83.8 & 2.8 \\
\hline D \& Gall & 39 & 100.0 & 20.5 & 79.5 & 0.0 \\
\hline Dundee & 167 & 97.6 & 7.4 & 92.0 & 0.6 \\
\hline Edinb & 256 & 92.6 & 38.4 & 61.6 & 0.0 \\
\hline Glasgw & 528 & 99.4 & 6.5 & 89.1 & 4.4 \\
\hline Inverns & 76 & 98.7 & 17.3 & 82.7 & 0.0 \\
\hline Klmarnk & 111 & 92.8 & 0.0 & 93.2 & 6.8 \\
\hline Krkcldy & 131 & 96.2 & 27.0 & 73.0 & 0.0 \\
\hline \multicolumn{6}{|l|}{ Wales } \\
\hline Bangor & 59 & 0.0 & & & \\
\hline Cardff & 429 & 0.0 & & & \\
\hline Clwyd & 66 & 0.0 & & & \\
\hline Swanse & 310 & 0.0 & & & \\
\hline Wrexm & 103 & 0.0 & & & \\
\hline England & 17,864 & 66.2 & 27.5 & 72.1 & 0.4 \\
\hline N Ireland & 535 & 99.3 & 28.1 & 71.9 & 0.0 \\
\hline Scotland & 1,675 & 97.3 & 13.9 & 83.7 & 2.5 \\
\hline Wales & 967 & 0.0 & & & \\
\hline UK & 21,041 & 66.5 & 25.9 & 73.4 & 0.7 \\
\hline
\end{tabular}

Blank cells denote no data returned by the centre or $<10$ patients in the renal centre or data completeness was $<50 \%$

centre range $76.0-100.0 \%)$ compared to male patients (84.6\%, centre range $67.5-95.3 \%)$.

\section{Changes in URR over time}

From 2002 there was an initial progressive increase in the percentage of patients achieving the current RA clinical practice guidelines (URR >65\%) until 2011, after which it has plateaued around 88\% (figure 6.3). Similarly, the median URR in UK haemodialysis patients rose from $71 \%$ to stabilise at $75 \%$ since 2011 .

\section{Variation of achieved URR with time on dialysis}

The proportion of patients who attained the UK RA clinical guideline for URR was greater for those who had been treated by haemodialysis for two years or longer compared to those who had been dialysing for $<6$ months (figure 6.4). For all strata of dialysis vintage, marked improvement in the proportion of patients receiving the sessional target dose of haemodialysis has plateaued in recent years.

\section{Changes in URR for incident patients}

The median sessional URR during the first quarter after starting haemodialysis treatment in the UK was $67.0 \%$ (centre range 58.5-76.0\%) (figure 6.5a) for incident HD patients in 2015. At the end of one-year follow-up, the median URR had increased to $73.0 \%$ (centre range 68.0-83.0\%) (figure 6.5b). More centres are included in the analysis this year due to the threshold for centre inclusion being relaxed to include centres returning data for at least ten patients rather than a minimum of 20 patients.

There was evidence that the median sessional URR during the first three months after starting haemodialysis 


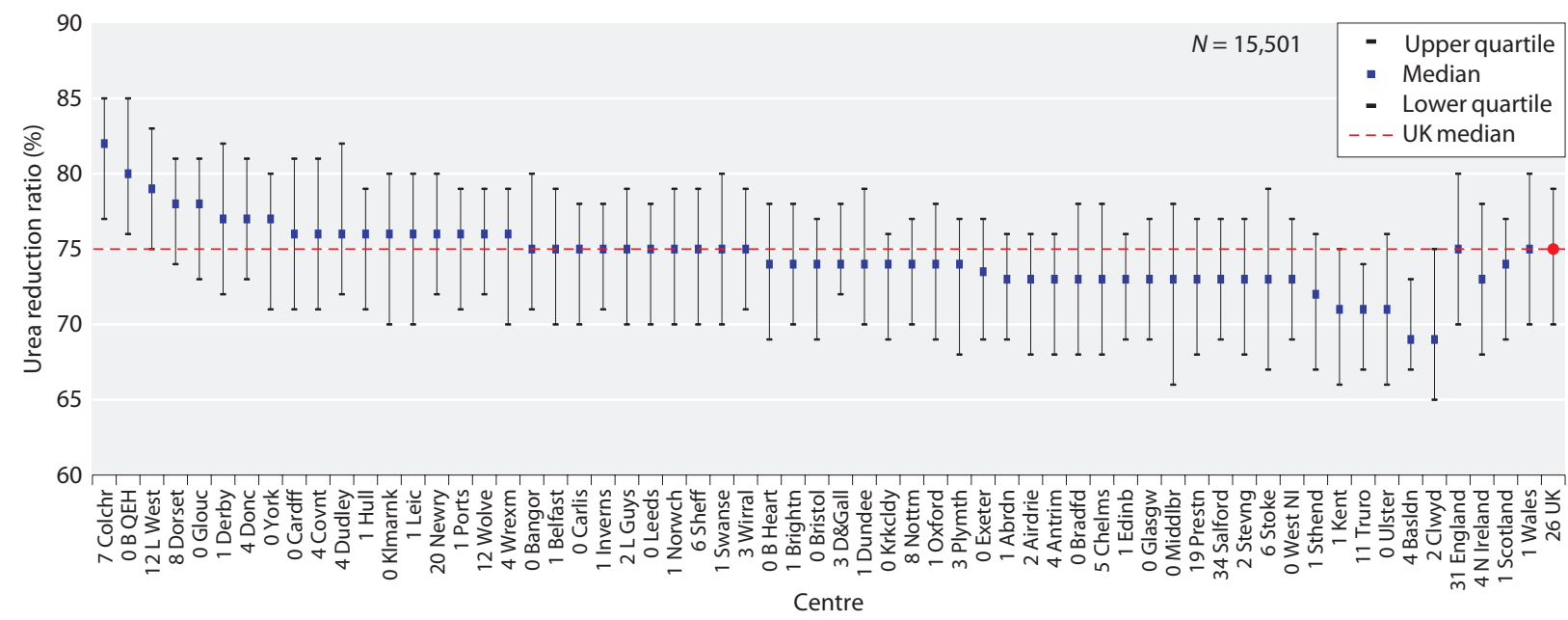

Fig. 6.1a. Median URR achieved in prevalent patients on HD by centre, 30/9/2016

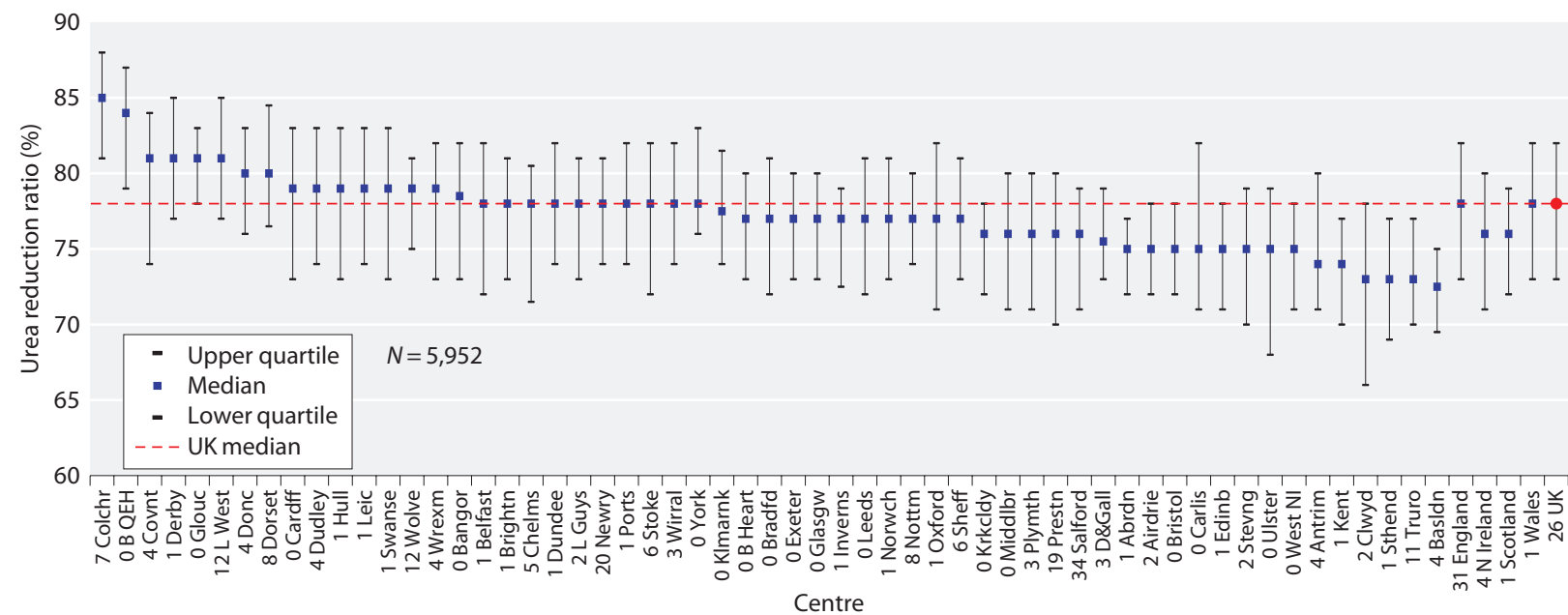

Fig. 6.1b. Median URR achieved in female prevalent patients on HD by centre, 30/9/2016

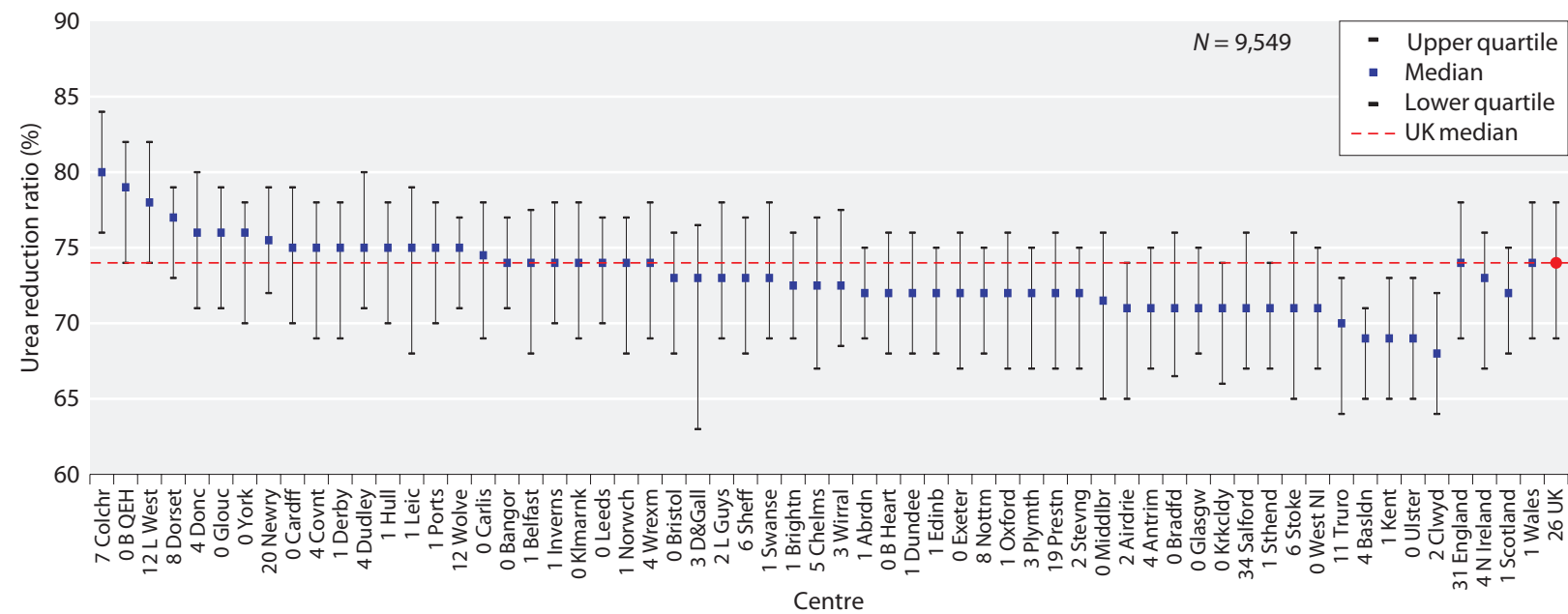

Fig. 6.1c. Median URR achieved in male prevalent patients on HD by centre, 30/9/2016 


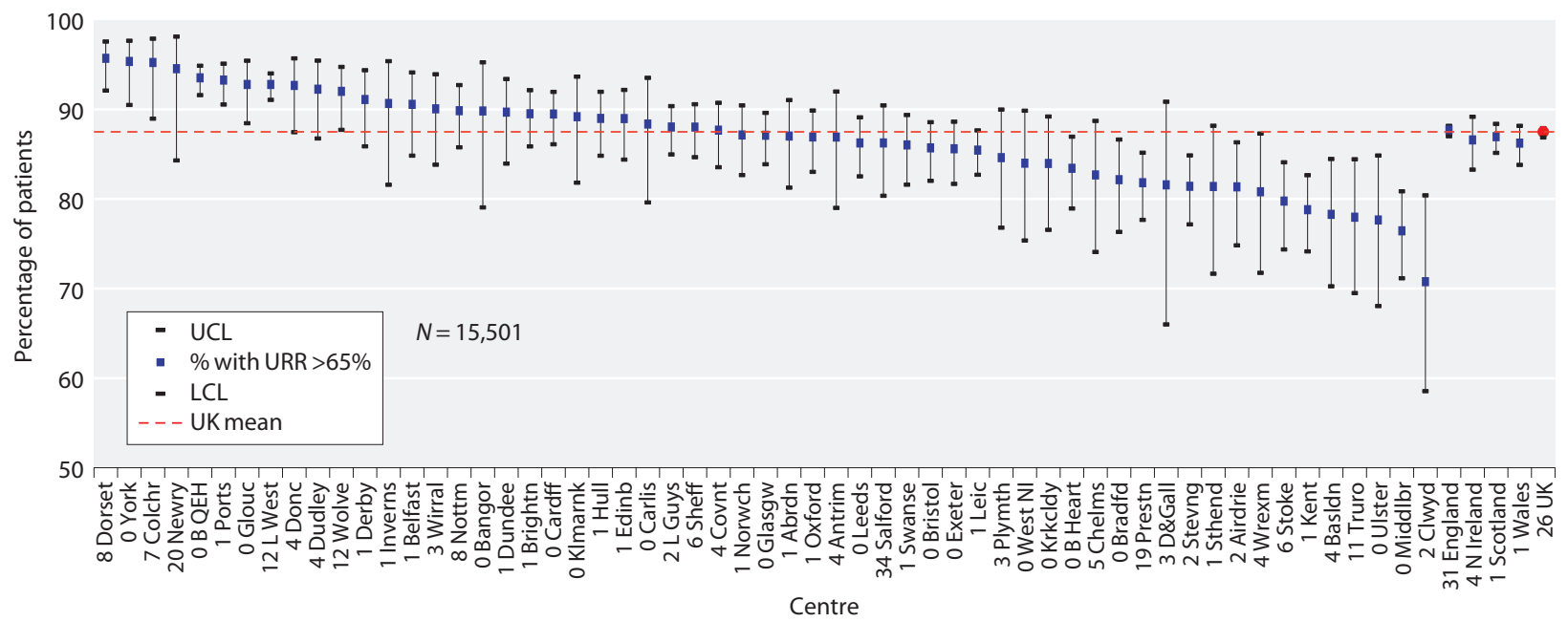

Fig. 6.2. Percentage of prevalent patients on HD with URR $>65 \%$ by centre, $30 / 9 / 2016$
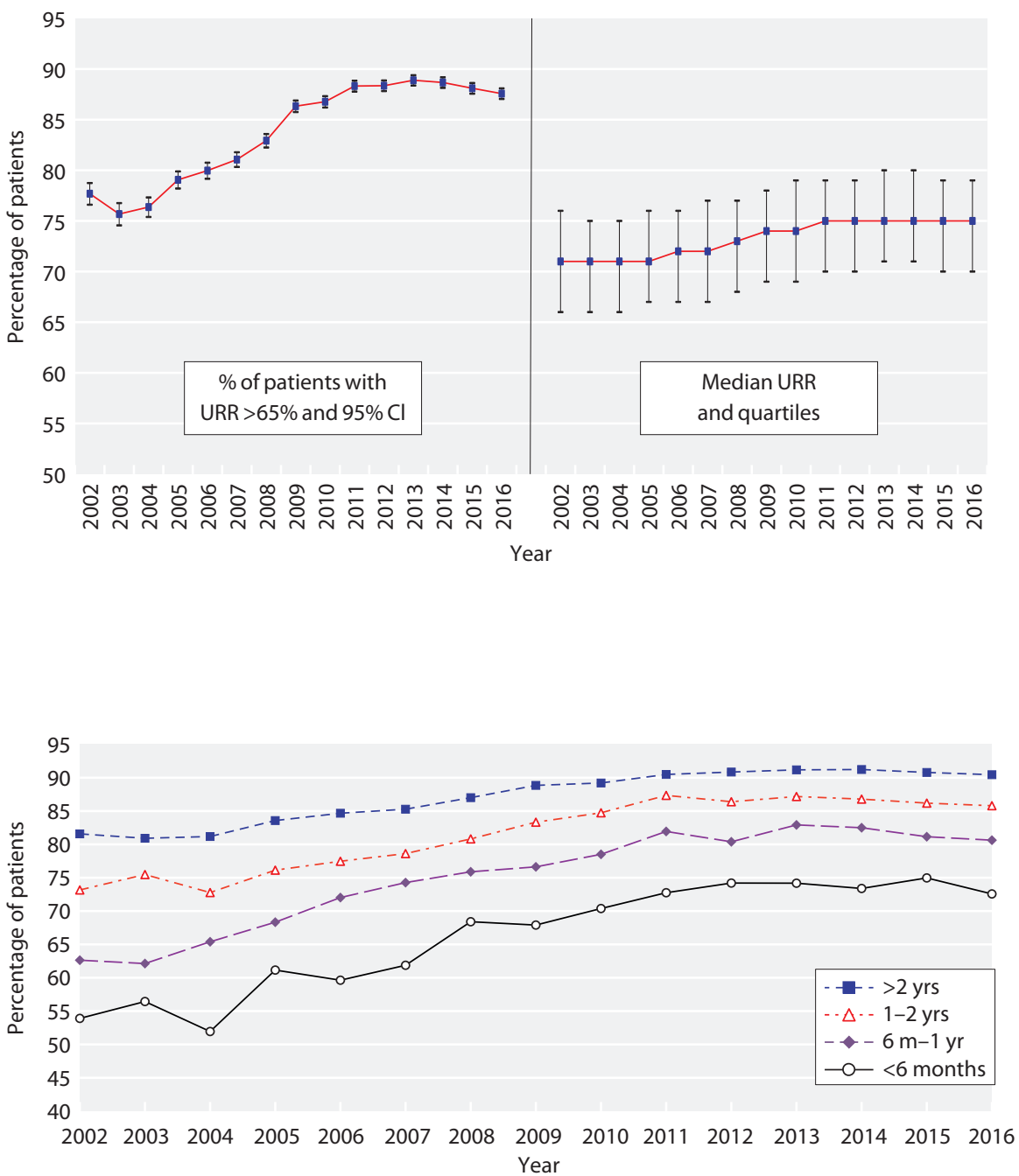

Fig. 6.3. Change in the percentage of prevalent patients on HD with URR $>65 \%$ and the median URR between 2002 and 2016

Fig. 6.4. Percentage of prevalent patients on $\mathrm{HD}$ achieving URR $>65 \%$ by time on RRT between 2002 and 2016

Pyart/Magadi/Steenkamp/Davenport 


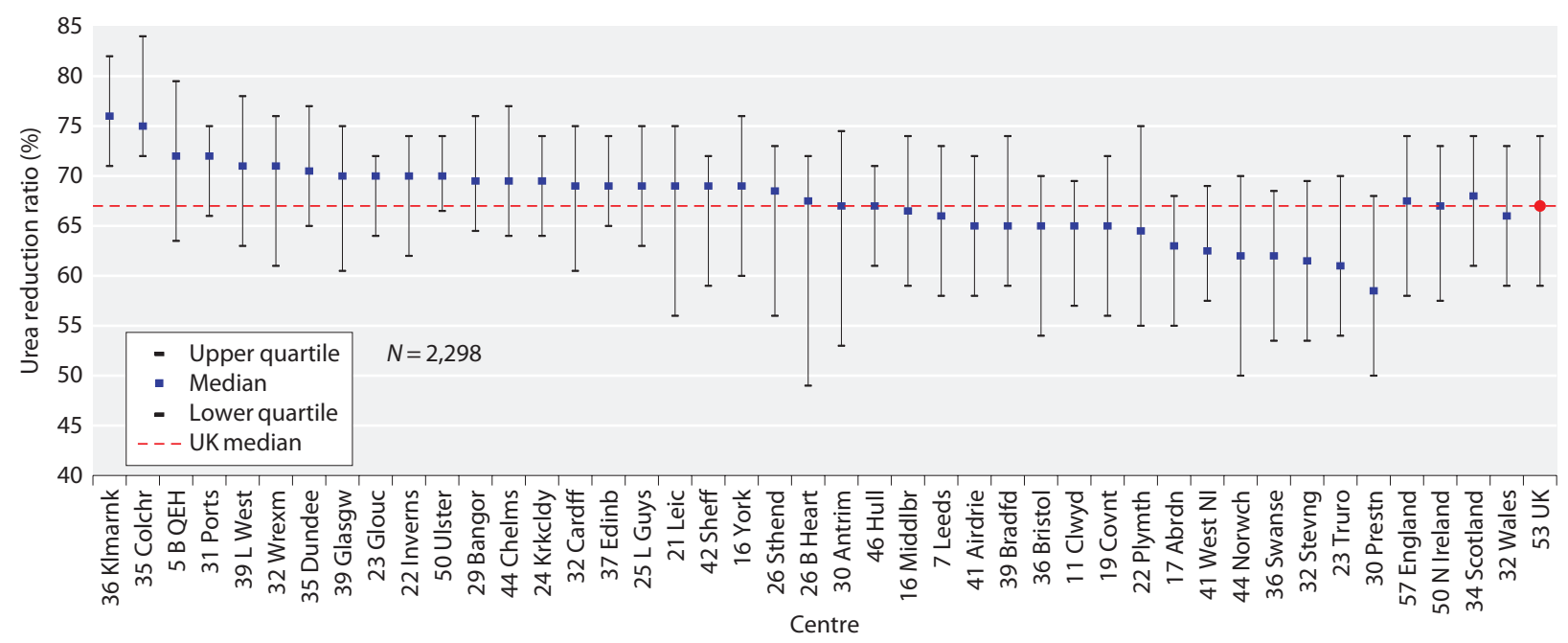

Fig. 6.5a. Median URR in the first quarter of starting RRT in incident patients who started HD in 2015

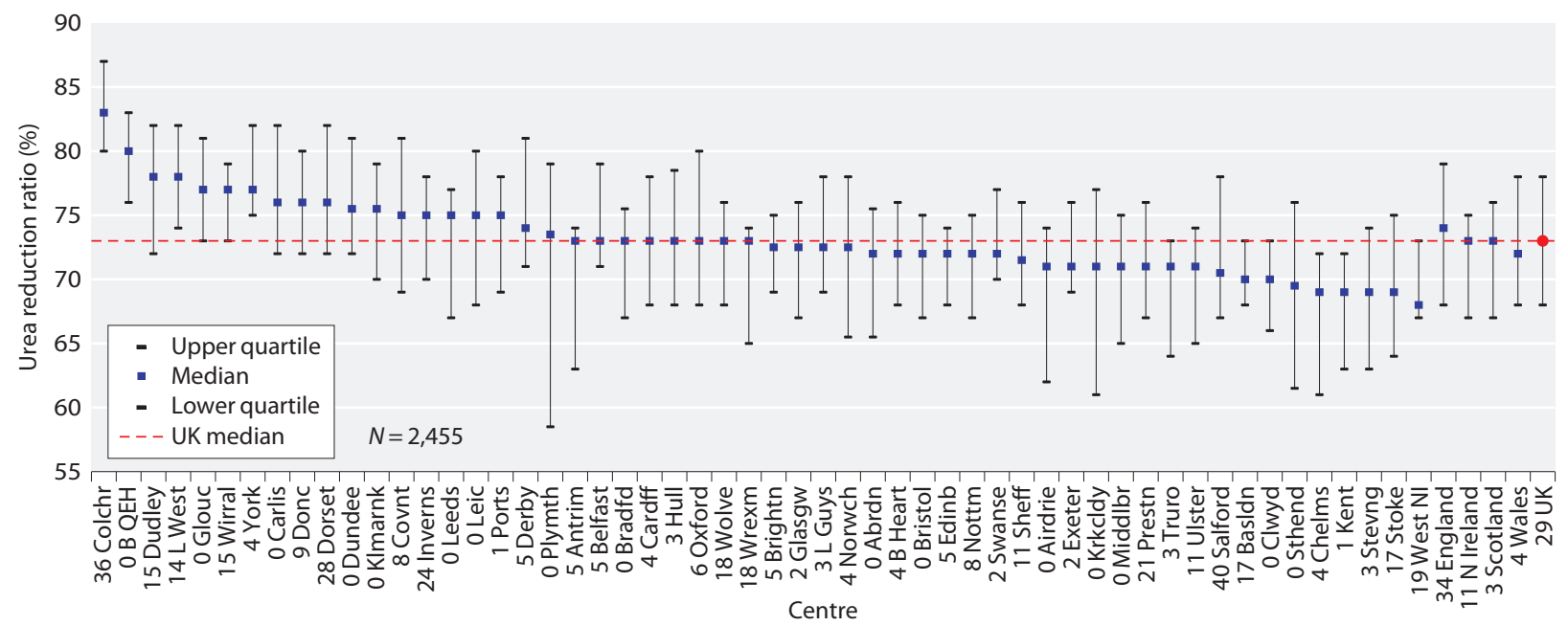

Fig. 6.5b. Median URR one year after starting RRT for incident patients who started HD in 2015

was lower for patients aged $<70$ years (median URR $66.0 \%)$ compared to patients older than $\geqslant 70$ years (median URR 69.0\%). Similarly, at the end of the first year of haemodialysis the median sessional URR was again lower for patients aged $<70$ years (median URR $73.0 \%$ ) versus $\geqslant 70$ years of age (median URR $74.0 \%$ ).

\section{Haemodialysis session duration for prevalent \\ HD patients}

For those centres which returned data, the majority of prevalent patients $(73.4 \%)$ dialysed between 4-5 hours, with $25.9 \%$ dialysing less than four hours per session, and only $0.7 \%$ dialysing for more than five hours (table 6.4). However, there were marked differences between centres, with between 1-85\% of patients reported to be dialysing less than four hours. Median URR was similar for patients dialysing longer $(\geqslant 4$ hours) versus shorter dialysis sessions ( $<4$ hours).

\section{Haemodialysis session frequency for prevalent HD patients}

Dialysis frequency data were available for $69.7 \%$ of patients (table 6.3) in 2016 compared with 68.7\% in 2015. Although $95.4 \%$ of all prevalent haemodialysis patients dialysed thrice weekly, there were marked differences in centre practices. Centres reported dialysing between $0.0-18.9 \%$ of patients twice weekly or less, and between $0.0-15.2 \%$ more than thrice weekly. Two centres 
reported dialysing $>10 \%$ of patients less than thrice weekly and four centres more often than thrice weekly. The sessional URR was lower with lower dialysis frequency (median URR $71.6 \%$ for prevalent HD patients dialysing $<3$ times per week versus a median URR of $75.0 \%$ for patients dialysing $\geqslant 3$ times per week).

\section{Discussion}

Haemodialysis is a life-sustaining treatment for patients with end stage kidney disease. In addition to the clearance of azotaemic toxins, the dialysis prescription encompasses volume control, maintenance of acidbase status and mono- and di-valent ion homeostasis. Dialysis adequacy is defined in the current RA and international clinical guidelines by dialyser urea clearance. Target dialyser urea clearance of $70 \%$ is recommended to consistently achieve the minimum URR of $>65 \%$ in as many patients as possible [12-14]. A minimum dialysis adequacy appears to be necessary for patient wellbeing [1], but the benefits of higher clearance and the optimal dialysis dose have not been well defined [2-5]. The older, more comorbid demographic of the current dialysis cohort may differ from previously studied populations although UKRR data has consistently, somewhat paradoxically, shown higher sessional urea clearance amongst older patients [15-17]. Muscle mass declines with age [15], and dialysis patients with less muscle mass are less physically active [16] and have lower energy expenditure [17]. So, one may have expected higher dialyser urea clearances delivered to the younger rather than older patients [18]. This apparent greater dialyser urea clearance in the older patient may be due to a mathematical confounder, in that it is easier to achieve a higher percentage urea clearance in a smaller patient with a lower pre-dialysis serum urea concentration compared to that in a heavier patient with a higher starting urea [19], and this confounder not only affects urea reduction ratio, but also Kt/Vurea [20, 21]. As there is an association between muscle mass and body surface area, then as Kt/Vurea underestimates clearance in patients with increased body mass index, and overestimates clearance in those with smaller body mass index [22], an adjustment for body surface area or energy expenditure may be more appropriate $[18,23]$.

Men and women differ in size, body composition and in their rates of resting energy expenditure all of which can contribute to lower dialyser urea clearance being needed in women to achieve a higher URR [16, 18]. Observational studies and post hoc analyses of the HEMO study have suggested that women may benefit from a greater dialyser urea clearance than men $[24,25]$, and for the same urea dialyser clearance women would receive a lower effective clearance [20]. However, neither UK RA nor other clinical guidelines advocate different targets based on gender [12]. It is therefore reassuring that in the UK, the median sessional URR remained higher for women than men to prevent lower dialysis dosing [20].

Following increases in the proportion of UK haemodialysis patients achieving target URR from 2002 until 2010 , this has since stabilized around $88 \%$ for the prevalent population. Standardised sampling technique and improved haemodialysis technology may have contributed to the earlier improvement [26]. The subsequent plateau in target attainment likely reflects the reality that not all established dialysis patients will consistently achieve the target URR, for example due to poorly functioning vascular access, cardiovascular intolerance on the day of urea sampling, or patients receiving palliative dialysis [21]. However, the marked inter-centre variability in the proportion of patients achieving the URR minimum of $>65 \%$, ranging from $70.7-95.7 \%$ of patients suggests a centre practice effect. Our current analysis makes no adjustment for centre differences in terms of patient case-mix, patient non-adherence to dialysis session length or practice differences such as high flux dialysis or haemodiafiltration. Residual renal function is not accounted for in the URR calculation and centre practice differences around early versus delayed start dialysis as well as whether centres practice an incremental approach to initiating dialysis may account for some of the differences observed [27]. The effect of residual renal function most likely accounts for the increase in URR observed in the incident haemodialysis patients from the first quarter to the final quarter URR returns, as shown by one centre increasing from $<60 \%$ to $>70 \%$.

In the UK, centres receive sessional payments, initially introduced to encourage more frequent dialysis. However, only some 2\% of patients dialysing in England were reported to dialyse more than thrice weekly although there was variation between centres, as four centres reported dialysing over $10 \%$ of their patients more frequently. The UK Renal Association clinical guidelines recommend that patients should have thrice weekly dialysis [12], and although on average only around $3 \%$ of patients dialysed twice or less frequently, again practice varied markedly with centres reporting a range of $0 \%$ to $19 \%$. The UKRR were unable to determine 
whether this was due to patient-case mix, centres taking into account residual renal function, or resource limitations; although on enquiry to individual centres it would appear to be a combination of patient-case mix [21], centres measuring residual renal function and practicing incremental dialysis [27].

The UK Renal Association clinical guidelines recommend that patients without residual renal function should dialyse for four hours [12]. Most prevalent patients dialysed between 4-5 hours, however over a quarter (25.9\%) dialysed for shorter times ( $<4$ hours) and less than $1 \%$ dialysing for longer ( $>5$ hours). Further marked inter-centre variability was noted in session duration with a wide range $(0.0-84.8 \%)$ of patients dialysing for less than four hours. Twenty six of the 53 centres that provided data on time dialysed (49\%), dialysed more than $20 \%$ of patients for $<4$ hours. The guidelines date from a time when low-flux dialysers were the standard, and prior to the improvements in dialyser technology and introduction of other modalities such as haemodiafiltration [26]. However, although greater urea clearance can potentially be achieved with shorter session times, this does not imply that other azotaemic toxins [28-31], as well as sodium would be equally cleared
[32]. Once again, the UKRR were unable to determine whether centres with higher proportions of patients having shorter dialysis sessions was due to patient casemix, patient wishes, intolerance of dialysis, or clinician factors, including considering residual renal function.

The pros and cons of using URR as a measure of dialysis adequacy continue to be debated $[11,21,30$, 31]. It does not account for the clearance of other larger molecules, nor does it reflect other important aspects of dialysis such as session length, volume control, sodium balance and the correction of metabolic acidosis all of which can potentially impact patient outcomes [29, 32]. However, no consensus has yet emerged on alternative markers of HD adequacy [33]. Practically, URR has been relatively simple to collect and the resulting data completeness has made it the easier to analyse for the UKRR.

It is planned to work with centres to ensure dialysis session data can be used to augment the overall data completeness. As data collection expands, $\mathrm{Kt} / \mathrm{V}$ and dialysis prescription practice will be used to improve the analysis.

Conflicts of interest: the authors declare no conflicts of interest

\section{References}

1 Gotch FA, Sargent JA. A mechanistic analysis of the National Cooperative Dialysis Study (NCDS). Kidney Int. 1985 Sep;28(3):526-34

2 Owen WF, Lew NL, Liu Y, Lowrie EG, Lazarus JM: The Urea Reduction Ratio and Serum Albumin Concentration as Predictors of Mortality in Patients Undergoing Haemodialysis. N Engl J Med 1993;329:1001-1006

3 Held PJ, Port FK, Wolfe RA, Stannard DC, Carroll CE, Daugirdas JT, Bloembergen WE, Greer JW, Hakim RM: The dose of haemodialysis and patient mortality. Kidney Int 1996;50:550-556

4 Eknoyan G, Beck GJ, Cheung AK, Daugirdas JT, Greene T, Kusek JW, Allon M, Bailey J, Delmez JA, Depner TA, Dwyer JT, Levey AS, Levin NW, Milford E, Ornt DB, Rocco MV, Schulman G, Schwab SJ, Teehan BP, Toto R; Haemodialysis (HEMO) Study Group. Effect of dialysis dose and membrane flux in maintenance haemodialysis. $\mathrm{N}$ Engl J Med. 2002; 347(25):2010-9

5 Depner TA: Assessing adequacy of haemodialysis: urea modeling. Kidney Int 1994;45:1522-1535

6 Kumar S, Khosravi M, Massart A, Potluri M, Davenport A. The effects of racial differences on body composition and total body water measured by multifrequency bioelectrical impedance analysis influence delivered $\mathrm{Kt} / \mathrm{V}$ dialysis dosing. Nephron Clin Pract. 2013;124(1-2):60-6

7 Couchoud C, Jager KJ, Thomson C, et al. Assessment of urea removal in haemodialysis and the impact of the European best practice guidelines, Nephrol Dial Transplant, 2009;24:1267-1274)

8 Moret KE1, Grootendorst DC, Dekker FW, Boeschoten EW, Krediet RT, Houterman S, Beerenhout CH, Kooman JP; NECOSAD Study Group. Agreement between different parameters of dialysis dose in achieving treatment targets: results from the NECOSAD study. Nephrol Dial Transplant. 2012 Mar;27(3):1145-52

9 Geddes CC, Traynor J, Walbaum D, Fox JG, Mactier RA. A new method of post-dialysis blood urea sampling: the 'stop dialysate flow' method. Nephrol Dial Transplant. 2000 Apr;15(4):517-23

10 Daugirdas JT, Greene T, Depner TA, et al. Factors that affect postdialysis rebound in serum urea concentration, including the rate of dialysis: results from the HEMO Study, J Am Soc Nephrol, 2004;15: 194-203

11 Vanholder R, Glorieux G, Eloot S. Once upon a time in dialysis: the last days of Kt/V? Kidney Int. 2015 Sep;88(3):460-5

12 UK Renal Association Clinical Practice Guidelines Committee Haemodialysis, 2009 http://www.renal.org/wp-content/uploads/2017/ 06/haemodialysis-5th-edition-1.pdf

13 European Best Practice Guidelines Expert Group on Haemodialysis. Nephrol Dial Transplant 2002:17(suppl 7):S16-S31

14 Rocco M, Daugirdas JT, Depner TA, Inrig J, Mehrotra R, Rocco MV, Brereton L. KDOQI Clinical Practice Guideline for Hemodialysis Adequacy: 2015 Update. American Journal of Kidney Diseases, 2015;66(5): 884-930

15 Greenhall GH, Davenport A. Screening for muscle loss in patients established on peritoneal dialysis using bioimpedance. Eur J Clin Nutr 2017 Jan; 71(1):70-75

16 Oliveira B, Sridharan S, Farrington K, Davenport A. Comparison of resting energy equations and total energyexpenditure in haemodialysis patients and body composition measured by multi-frequency bioimpedance. Nephrology (Carlton). 2017 Jul 13. doi: 10.1111/ nep. 13112

17 Hung R, Sridharan S, Farrington K, Davenport A. Comparison of estimates of resting energy expenditure equations in haemodialysis patients. 
Int J Artif Organs. 2017;Mar 27:0. doi: 10.5301/ijao.5000575. PMID: 28362048

18 Sridharan S, Vilar E, Davenport A, Ashman N, Almond M, Banerjee A, Roberts J, Farrington K. Scaling Hemodialysis Target Dose to Reflect Body Surface Area, Metabolic Activity, and Protein Catabolic Rate: A Prospective, Cross-sectional Study. Am J Kidney Dis. 2016 Sep 20. pii: S0272-6386(16)30407-3 PMID: 27663037]

19 Davenport A. Is Hemodialysis Patient Survival Dependent upon Small Solute Clearance $(\mathrm{Kt} / \mathrm{V})$ ?: If So How Can Kt/V be Adjusted to Prevent Under Dialysis in Vulnerable Groups? Semin Dial. 2017 doi: 10.1111/ sdi. 12566

20 Spalding EM, Chandna SM, Davenport A, Farrington K. Kt/V underestimates the haemodialysis dose in women and small men. Kidney Int 2008;74:348-355

21 Tattersall J, Farrington K, Gentile G, Kooman J, et al. Is Kt/V useful in elderly dialysis patients? Pro- and Con arguments. Nephrol Dial Transplant. 2018 Mar 16. pii: 4939512. doi: 10.1093

22 Davenport A. Differences in prescribed Kt/V and delivered haemodialysis dose-why obesity makes a difference to survival for haemodialysis patients when using a 'one size fits all' Kt/V target. Nephrol Dial Transplant. PMID: 23787543

23 Davenport A, Peters SA, Bots ML, Canaud B, Grooteman MP, Asci G, Locatelli F, Maduell F, Morena M, Nubé MJ, Ok E, Torres F, Woodward M, Blankestijn PJ. Higher convection volume exchange with online haemodiafiltration is associated with survival advantage for dialysis patients: the effect of adjustment for body size. Kidney Int. 2016 Jan;89(1):193-

24 Depner T, Daugirdas J, Greene T, Allon M, Beck G, Chumlea C, Delmez J, Gotch F, Kusek J, Levin N, Macon E, Milford E, Owen W, Star R,
Toto R, Eknoyan G, Hemodialysis Study Group. Dialysis dose and the effect of gender and body size on outcome in the HEMO Study. Kidney Int. 2004;65(4):1386

25 Port FK, Wolfe RA, Hulbert-Shearon TE, McCullough KP, Ashby VB, Held PJ. High dialysis dose is associated with lower mortality among women but not among men. Am J Kidney Dis. 2004;43(6): 1014

26 Davenport A. How can dialyser designs improve solute clearances for haemodialysis patients? Hemodial Int. 2014 Oct;18(suppl 1):S43-7

27 Wong J, Vilar E, Davenport A, Farrington K. Incremental haemodialysis. Nephrol Dial Transplant. 2015 Oct;30(10):1639-48. Epub 2015 Jun 1

28 Lowrie EG: The Kinetic Behaviors of Urea and Other Marker Molecules During Haemodialysis. Am J Kidney Dis 2007;50:181-183

29 Marshall MR, Byrne BG, Kerr PG, McDonald SP: Associations of hemodialysis dose and session length with mortality risk in Australian and New Zealand patients. Kidney Int 2006;69:1229-1236

30 Eloot S, Van Biesen W, Dhondt A, Van de Wynkele H, Glorieux G, Verdonck P, Vanholder R: Impact of hemodialysis duration on the removal of uremic retention solutes. Kidney Int 2007;73:765-770

31 Eloot S, Torremans A, De Smet R, Marescau B, De Deyn PP, Verdonck P, Vanholder R: Complex Compartmental Behavior of Small WaterSoluble Uremic Retention Solutes: Evaluation by Direct Measurements in Plasma and Erythrocytes. Am J Kidney Dis 2007;50:279-288

32 Davenport A. How best to improve survival in haemodialysis patients: solute clearance or volume control? Kidney Int. 2011;80(10):1018-20

33 Wong J, Sridharan S, Berdeprado J, Vilar E, Viljoen A, Wellsted D, Farrington K. Predicting residual kidney function in haemodialysis patients using serum $\beta$-trace protein and $\beta 2$-microglobulin. Kidney Int. 2016 May;89(5):1090-8 